\title{
Alimentação e Nutrição em Saúde Coletiva: constituição, contornos e estatuto científico
}

\author{
Food and Nutrition in Public Health: \\ constitution, contours and scientific status
}

M aria Lúcia M agalhães Bosi ${ }^{1}$

Shirley Donizete Prado ${ }^{2}$

\footnotetext{
${ }^{1}$ Programa de PósGraduação em Saúde Coletiva, Departamento de SaúdeComunitária, Faculdadede M edicina, UniversidadeFederal do Ceará. Bloco Didático, Rua Professor Costa M endes 1.608, $5^{\circ}$ andar, Rodolfo Teófilo. 60416-200 Fortaleza CE. malubosi@ufc.br ${ }^{2}$ Programa de Pós-Graduação em Alimentação, Nutrição e Saúde, Núcleo de Estudos sobre Cultura e Alimentação, Departamento deN utrição Social, Instituto deNutrição, Universidade do Estado do Rio deJaneiro.
}

Abstract This paper aims to examine the route on which Food and Nutrition in Public Health was build in the Brazilian context, from its fields of origin, identifying tensions and convergences, seeking to demarcate its boundaries and to characterize its status within the scientific field. We seek to evince the existence of a movement marked by thefruitful encounter between thefield of "Public H ealth" and a portion of the field of "Food and Nutrition", or more precisely, one of their cores, starring actors oriented by knowledge distinguished from other nuclei in this field. Such phenomena, that we postulate as outcomes of the contact nuclei of knowledge that identify the Public H ealth with the field of "Food and Nutrition", led to a specific core of distinct knowledge and praxis in this context corresponds to what we call "Food and Nutrition in Public Health". This is a process marked from the outset by tensions between the biological and social paradigms, becoming the one hand, asa major challengeto befaced, and secondly, as a promising way for the approach between different fields of science, both the more practical, such as those targeted to conceptual reflection. Key words Scientific field, Knowledge and practice nuclei, Food, N utrition, Public Health
Resumo Este artigo se propõe a examinar o percurso de constituição da Alimentação e N utrição em Saúde Coletiva, no contexto brasileiro, a partir deseus campos de origem, identificando tensões e confluências, buscando demarcar seus contornos e caracterizar seu estatuto no interior do campo científico. Procuramos evidenciar a existência de um movimento marcado pelo encontro profícuo entre o campo da "Saúde Coletiva" e uma parcela do campo da "Alimentação e Nutrição", ou, mais precisamente, um dos seus núcleos, protagonizado por atores orientados por saberes diferenciados dos demais núcleos nesse campo. Tais fenômenos, que postulamos como desfechos do contato dos núcleos desaberesque identificam a SaúdeC ol etiva com o campo da "Alimentação e Nutrição", deram origem a um núcleo específico de saberes, bem como a práxis distintas, nesse âmbito correspondendo ao que denominamos "Alimentação e Nutrição em Saúde Coletiva". Trata-se de um processo marcado, desde o início, por tensões entre os paradigmas biológico e social, configurando-se, por um lado, como um importante desafio a ser enfrentado e, por outro, como um caminho promissor para a aproximação entre distintos campos da ciência, tanto os de cunho mais prático como os dirigidos à reflexão conceitual.

Palavras-chave Campo científico, N úcleos de conhecimentos e práticas, Alimentação, Nutrição, SaúdeColetiva 
Introdução

Este artigo se propõe a visitar a Alimentação e Nutrição em SaúdeC oletiva (ANSC), no contexto brasileiro, examinando seu movimento de constituição na interface de seus campos de origem, identificando tensões e confluências, visando demarcar seus contornos e caracterizar seu estatuto no interior do campo científico.

A motivação que conduz sua elaboração advém, em parte, da "nebulosidade" observada nos delineamentos da Alimentação e N utrição (AN) no âmbito da Saúde Coletiva (SC), considerados como domínios específicos, ambos comple xos einterdisciplinares, aqui caracterizados como "campos", nos quais convivem distintos saberes.

O conceito de "campo", referido ao espaço da ciência, encontra uma definição estratégica em Pierre Bourdieu ${ }^{1}$, autor que o define como um espaço de luta concorrencial no qual o que está em jogo são os monopólios da autoridade científica [...] e da competência científica [...] que são socialmente outorgadas. Dessa forma, embates epistemológicos revelam-se como intrinsecamente políticos, tal como se evidencia nos conflitos e disputas que se processam nos planos conceitual e da práxis. Assim, examinar o movimento dos saberes na constituição de campos implica tratar com tensões "paradigmáticas", ou seja, tensões entre estruturas conceituais quetambém operam no interior do campo, no que concerne tanto às concepções quanto às práticas delas decorrentes ou a elas relacionadas².

Paradigmas seriam, portanto, estruturas de pensamento partilhadas por uma comunidade, "mas imersas em relações de poder", sem o que não se podem compreender fenômenos como a emergência e a hegemonia conquistada por cada um deles em dado momento histórico, bem como eventuais superações.

Retomando a "nebulosidade" à qual nos referimos ao tomar as interseções entre os campos focalizados - AN eSC - , esta, a nosso ver, se constitui como um fenômeno que conjuga distintos planos, caracterizando-se, conforme já aludido, como questão epistemológica e política, com desdobramentos em várias esferas. Epistemológica, haja vista questões vinculadas à identificação dos objetos, conceitos e métodos que marcam cada um dos âmbitos específicos (AN e SC) e, mais queisto, o que ocupa a inter seção entre eles, constituindo, conforme examinaremos adiante, um núcleo específico de saberes e práticas, com características próprias e distintas dos campos originários, evidentemente guardando suas "marcas de origem". Política, uma vez que, retomando PierreBourdieu, qualquer discussão epistemológica é "indissociavelmente" política. Portanto, ao nos referirmos ao político, cabe dialetizá-lo com os demais planos, uma vez que disputas epistemológicas, a um só tempo, derivam de e se expressam em projetos distintos, ora consensuais, ora conflituosos, voltados a igual mentedistintos projetos sociais em disputa pela hegemonia ${ }^{3}$.

AN e SC se revelam como campos específicos, bem como redes de formações que guardam mútua autonomia, o que também é fato para seus percursos de constituição e para os atores e protagonistas que neles vêm atuando, nos diferentes espaços de prática. Para os fins da discussão aqui pretendida, importa assinalar que importantes interações se processaram entre ambos os campos - AN e SC - na história e não se mostram claras, tampouco foram examinadas na literatura relativa a esse objeto, de modo a evidenciar aproximações, por vezes tensas, distanciamentos e interfaces. Tais movimentos, a despeito de não se mostrarem claros, vêm configurando outro âmbito de saberes e práticas - a "Alimentação e Nutrição em Saúde Coletiva" conforme procuraremos argumentar. Para tanto, a pergunta de partida demarcada como desafio neste artigo pode ser assim sintetizada: "qual o escopo do queaqui estamos denominando Alimentação e Nutrição em Saúde Coletiva?"

Dada a complexidade da questão que nos desafia, nossa pretensão não é esgotar ou mesmo examinar todas as dimensões que seimpõem em uma análise dessa envergadura, sobretudo no espaço exíguo de que dispomos. Nosso intuito é, tão somente, oferecer alguns subsídios visando fomentar um debate mais rigoroso e sistemático acerca da constituição e da configuração atual da ANSC, como o tema parece merecer, uma vez que muitas questões permanecem latentes nas agendas de ambos os campos originários - AN eSC.

Dentre os percursos que se nos apresentaram para a consecução desse desafio, optamos por (re)visitar ambos os domínios - AN e SC - buscando identificar os saberes que os constituem, os movimentos que se processam entre eles e, assim, visualizar os contornos do que aqui se postula como ANSC. Para tanto, parece nos útil o constructo "núcleos de saberes", correspondendo ao que Nunes ${ }^{4}$ define como "espaços e formações disciplinares". Ressalvamos que "núcleo" é um conceito que transita em vários domínios disciplinares, revestindo-secom distintos significados, exigindo sua definição. Quanto ao emprego de 
"núcleos de saberes" no âmbito da Saúde Coletiva, identificamos na literatura ${ }^{5}$ terminologias similares, porém com significados distintos daquele adotado neste texto, já aqui demarcado.

Considerando o acúmulo de reflexões acerca da SC, podemos afirmá-la como espaço já institucionalizado, legitimado e cientificamente consolidado, conforme assinalado por vários autores $^{6-9}$. Sua constituição se fundamenta em três núcleos de saberes: a Epidemiologia; (a parcela das) CiênciasH umanas eSociaisquetransitanesse campo; e um terceiro domínio, que - sob múltiplos rótulos - se ocupa da "Política, do Planejamento ou da Planificação e da Gestão de Sistemas de Saúde". Cabe registrar a existência de movimentos no sentido da constituição de outros núcleos, a exemplo daquele voltado para o trabal ho e para questões ambientais a el e associadas, reivindicando uma autonomia que ainda demanda afirmação, sobretudo no plano epistemológico. 0 exame dos três núcleos principais, contextualizando-os na trajetória de conformação da SC, constitui o cerne do exercício que empreen deremosa seguir como etapa necessária no percurso aqui pretendido.

\section{O campo da Saúde Coletiva}

As origens da Saúde Pública devem ser buscadas nas condições sanitárias produzidas pela emergência do capitalismo na Europa, vinculadas à industrialização, urbanização desordenada e aumento da miséria relativa ${ }^{10}$. Tal como realçado por autores como N unes ${ }^{4}$, encontramos na obra deFoucault ${ }^{11}$ os vínculos da M edicina Social com os projetos conhecidos como polícia médica, medicina urbana e medicina da força de trabaIho, respectivamente desenvolvidosnaAlemanha, na França ena Inglaterra ${ }^{12}$. Análises consistentes como as desenvolvidas por Nunes ${ }^{4,13,14}$ evidenciam que a constituição da M edicina Social e, posteriormente, a da Saúde Pública e a da Saúde Coletiva vinculam-se estreitamente às políticas de saúde, expressando as especificidades do contexto sócio-histórico em que emergem.

No caso da Saúde Coletiva, trata-se de um campo científico e um âmbito de práticas cujas origens se relacionam com o projeto preventivista emergente na segunda metade dos anos 50 do século passado ${ }^{4}$, visando superar dialeticamente a SaúdePública convencional eo modelo biomé dico, desenvolvendo-se historicamente, no Brasil, a partir dos anos 1970. Como movimento, articula-se em oposição a vários outros que 0 antecederam, tais como o Higienismo, a M edicina Preventiva e a M edicina Comunitária ${ }^{15,16}$.

Este campo científico, em permanente (re) construção, se funda na interface das Ciências Naturais e das Ciências Humanas e Sociais, com uma natureza epistemológica e uma prática política diferenciadas. No que concerne à sua constituição como campo de saberes e práticas, os conhecimentos nele produzidos podem (tal como se observa em relação aos demais no setor saúde) ser aplicados por distintos atores, mas confluímos para a vertente que sustenta existir um corpo básico que dá identidade ao "pensar" e ao "fazer" em Saúde Coletiva, inspirado em um conjunto de valores ("ser") ${ }^{10}$.

No que concerne ao plano epistemológico, reconhece-se que a Saúde Coletiva, tal como e ainda mais fortemente que a Saúde Pública, não constitui especialidade médica, sendo suas "interseções cada vez mais amplas e profundas com as Ciências Humanas e Sociais" e outros domínios disciplinares ${ }^{16}$, consoante a interdisciplinaridade ou a transdisciplinaridade exigidas pelos objetos de que se ocupa. Situada, em linhas muito gerais, sua trajetória, cabe recuperar e examinar sua composição, para o que retomaremos al gumas propostas que parecem deutilidade para a consecução desse objetivo.

Parece ser consenso, na área, que os três núcleosmencionados expressam a constituição epistemológica do campo, embora seja importante reconhecer um debateque se polariza entrea fragmentação ea interdisciplinaridadeno campo. $\mathrm{Na}$ primeira vertente, nos diz Loyola ${ }^{17}$ : $\mathrm{Na}$ ausência de um projeto político coletivo, capaz de aglutinar em uma só direção os esforços do conjunto de profissionais ededi sciplinas quecompõem a área, esta foi aos poucos se burocratizando e "disciplinarizando-se", ou seja, fechando-se em torno das diferentes disciplinas que compõem o campo nas suas principais áreas de concentração: Epidemiologia, Planejamento e Ciências Humanas. Já na perspectiva que advoga a interdisciplinaridade, afirma N unes 4 a imagem queassocio ao entendimento do campo é a de mosaico - conjunto formado por partes separadas, mas quese aproximam quando a compreensão dos problemas ou a proposta de práticas se situam além dos limites de cada "campo disciplinar", exigindo arranjos interdisciplinares. [...] Asidéias desenvolvidas atéestemomento pautam o campo da Saúde Coletiva como extenso e diversificado, refletindo a própria concepção ampliada de saúde em suas inúmeras interfaces.

$\mathrm{Na}$ impossi bilidade de, nos limites deste artigo, examinar em que medida tais posições cor- 
respondem ao movimento do campo e a proporção em que o projeto interdisciplinar se efetiva ou não, o que deixamos anotado para investimentos futuros, adotaremos os três núcleos de saberesjáantes mencionadosnão por simplesconvenção, mas porque se estabeleceram como parte do processo de constituição da área ${ }^{4}$.

O núcleo identificado como "Epidemiologia", que segundo Czeresnia ${ }^{18}$ tem por objeto a distribuição e os determinantes dos processos de saúde e doença em populações humanas, guarda movimentos que se debatem entre distintos investimentos que poderíamos situar entre dois pólos: um primeiro, empírico, buscando relações estatísticas entre "fatores causais" de doenças em populações e se concretizando em um fortíssimo avanço de metodologias etécnicas, especialmente daquelas voltadas à quantificação, desenvolven do artefatos cada vez mais complexos, ao tempo que sedistancia de reflexões teóricas e do "pensar a saúde"; e outro voltado para a esfera conceitual - constituindo seu objeto no processo saúde/doença -, englobando tanto as especificidades do biológico quanto as do contexto social, alicerçadas no pensamento crítico em saúde.

Algumas proposições de Barata ${ }^{19}$ evidenciam certos desfechos do balanço entre essas perspectivas: A el aboração ea utilização crescentes de técnicas de análises cada vez mais sofisticadas, nas pesquisas epidemiológicas, não se acompanharam de igual fortalecimento da reflexão teórica, favore cendo a identificação da epidemiologia como um método mais do que como uma ciência com objeto próprio.

Restringe-se, assim, a Epidemiologia à esfera da racionalidade "neutra", "objetiva", naturalizante, o que, em compasso com as tendências dominantes da ciência moderna, resulta em evidente hegemonia desse núcleo de conhecimentos sobre os demais no âmbito da Saúde Coletiva - notadamente, sobre os humanistas.

Não obstante essa posição de dominância científica, tal condição não impedequea Epidemiologia se defronte com resistências manifestas, externas ou internas a este núcleo. Assim, conforme já antecipado ao nos referirmos à polarização intrínsecaa essenúcleo, em meados de 1970 emergem críticas às teorias da causalidade, no sentido de não apenas mensurar, mas explicar 0 processo saúde-doença em populações humanas. Visando contextualizar socialmente, repensar o método eo processo de construção deenunciados científicos, cabe assinalar a contribuição da teoria da determinação social do processo saúde-doença, inserindo categorias analíticas com potencial crítico nas análises a partir de então desenvolvidas ${ }^{19}$.

Essa vertente, ao buscar nas conjunções sociais fundamentos para a Epidemiologia, sinaliza, ainda, para as interfaces com as $\mathrm{Ciências} \mathrm{Hu}$ manas e Sociais e com as políticas públicas no setor, evidenciando construções interdisciplinares. Tal cenário de embates que marca a Epidemiologia terá reflexos em outros campos, dentre eles a Alimentação e Nutrição, fazendo-se notar, em especial eoriginal mente, nalinha dos estudos sobre a fome no Brasil e desdobrando-se, posteriormente, em estudos sobre a obesidade e outros fenômenos, tal como veremos adiante.

Quanto ao núcleo da SC nomeado "Ciências Humanas e Sociais em Saúde", suas relações com os demais podem ser resumidas nas palavras de Loyola17: 0 aporte das ciências sociais, a partir dos anos 1970, através de suas teoriase metodologiasjá consolidadas, foi indispensável para o desenvolvimento e consolidação da área que, no campo da saúde, se tornou conhecida como Saúde Coletiva.

Ainda que vistas como disciplinas auxiliarese menos nobres ante a hegemonia do paradigma biomédico, as Ciências H umanas e Sociais foram abraçadas por alguns estudiosos do campo da Saúde como vias privilegiadas para "ousar pensar a saúde", demarcando, assim, seu lugar na SC. Salientem-se as reflexões sobre as próprias teorias e metodologias do campo, a exemplo das contribuições há pouco mencionadas, quando nos reportamos ao empreendimento da Epidemiologia crítica ou social, por elas inspirada. Além disso, conforme abordaremos adiante, quando examinarmos o núcleo das Políticas, planejamento e gestão em saúde, se poderá constatar o lugar das CHS como fundante desse referencial, revelando, conformejá assinalado por $\mathrm{Nunes}^{14}$, que, na base da inovação e da práxis da Saúde Coletiva, se localiza a presença desse núcleo específico. São importantes as palavras de Loyola ${ }^{17}$ ao afirmar que Graças a esse esforço, vários e importantes estudos capitaneados ou influenciados pelas ciências sociais e pelas ciências humanas começaram a ser desenvolvidos: sobrea determinação social da doença, as instituições e as políticas de saúde, as relações entre indivíduo e sociedade, sobre os sistemas de saúde, as representações sociais da doença, sobre as práticas de saúde oficiais e alternativas, as diferentes racionalidades terapêuticas, a história das doenças e das epidemias, as profissões médicas, os movimentos sociais em saúde e tantos outros.

Destaque deve ser dado à particular contribuição advinda das CHS às reflexões críticas sobre a própria constituição do campo da SC, seus 
dilemas, contradições, disputas e colaborações internas e externas. Dentre as várias contribuições, destacam-se reflexões sobre o objeto da SC edeseus núcleos de saberes e práticas e os aportes ao empreendimento do campo (SC), que impõe lidar com dimensões qualitativas e quantitativas; sujeito eestrutura; natureza ehistória; objetividade e subjetividade; dimensões sistematicamente trabal hadas, buscando religar o que a modernidade divorciou ${ }^{20}$. Ao contrário do quea visão das chamadas hard sciences postula, justifica-se, portanto, o caráter multidimensional das chamadas soft sciences, uma vez quenão existea possibilidade de uma única formulação teórica e metodológica quando espaço, tempo epessoa não são simplesmente variáveis, mas constituem parte integrante de processos históricos e sociais8.

Nesse movimento - ainda que persista o pre domínio da Epidemiologia - , as CHS vêm propiciando o fortalecimento epistemológico do campo e a geração de desdobramentos operacionais mais consistentes, tanto no âmbito das práticas em saúde quanto nos loci de formação e de geração de conhecimentos. Também respondem deforma decisiva pela própria constituição epistemológica da SC, ao "inocularem" seus elementos conceituais e metodologias no âmbito da "Epidemiologia" como também no das "Políticas, planejamento e gestão em saúde"; no primeiro caso, reconfigurando o núcleo; no segundo, fornecendo suas bases conceituais advindas de disciplinas como: ciência política, sociologia, administração, demografia e muitas outras.

Contudo, a despeito das recentes iniciativas nessa direção, julgamos importante salientar que a incorporação das CHS ainda não se deu em toda a sua plenitude, o que permitiria investimentos que pudessem incluir mediações e análises mais refinadas, sobretudo nas iniciativas voltadas a processos que impõem considerar o humano, ou seja, não só o que se passa na estrutura, mas na subjetividade produzida na e produtora da práxis na saúde ${ }^{21-23}$.

Quanto ao núcleo de saberes epráticas quese dirige às "Políticas, planejamento e gestão em saúde", este se constitui incorporando elementos conceituais oriundos das $\mathrm{CHS}$, enfatizando a dimensão política, as relações com o Estado e suas crises, a necessidade do planejamento e da gestão em âmbito populacional, em especial no contexto da crise dos anos 1970. Consoante a literatu$\mathrm{ra}^{24}$, esses componentes focalizam questões vinculadas a relações de poder, bem como aquelas referidas ao estabelecimento de diretrizes, planos e programas, sua implementação e avaliação.
Com tonalidades distintas, essenúcleo de produção de conhecimentos étambém marcado por tensões expressas na polarização entre a valorização da "intervenção" - dados os desafios da prática, grosso modo atravessados por ideologias diversas - ea "investigação" fundada em dimensões conceituais, sobre as quais também se debruça ainda que, a nosso ver, em menor escala. Quanto a isso, os anos 1980 foram marcantes nos debates de cunho teórico-metodológico, destacando-se os desdobramentos da crítica ao caráter instrumental do planejamento e sua articulação com o processo de reorientação da política de saúde ${ }^{23}$.

Cabe aqui uma distinção entre as nuanças da tensão paradigmática presente no núcleo Epidemiologia daquelas identificadas no âmbito da Política, Planejamento e Gestão em Saúde, ora examinado. 0 primeiro núcleo émarcado principalmente pelo embate entreabordagens hegemônicas, fundadas na val orização de métodos e técnicas de pesquisa, reduzindo o humano à effera da N atureza, e aquelas, minoritárias, que valorizam a contextualização histórica e social. Já no segundo núcleo, a tensão parecese dar no interior do próprio campo das Humanidades entre os investimentosdecaráter mais instrumental eaqueles voltados a seus objetos e teorias.

Em que pese a autonomia que esse núcleo tenha ou possa vir a construir no interior da Saúde Coletiva, sustentamos que, no plano epistemológico, ele se situa no âmbito das Ciências Humanas e Sociais, haja vista lançar mão do arcabouço teórico-metodológico que identifica esse lugar naciência moderna. Há que reconhecer que desse âmbito, efetivamente, um novo conjunto de questões aflora, com fortes implicações sobre o campo da AN e também para a SC, evidenciando-sena expressiva produção ena prática concreta nas Políticas de Alimentação e Nutrição, tema ao qual retornaremos adiante.

Do exposto se depreende que, como campo científico assumidamente interdisciplinar, a SC lida, portanto, com um amplo leque temático, atraindo e abrigando profissionais de diversas origens, "negociando" com configurações e epistemologias variadas, incursionando e fertilizando outros campos, tal como se dá quando a SC põefoco nas questões alimentares enutricionais. U ma vez que os desfechos desse "encontro" constituem o cerne do empreendimento neste texto, impõe-se, como próxima etapa, tal como procuramos desenvolver focalizando a SC, um exame do campo da Alimentação e Nutrição, suas origens, trajetória e constituição. 


\section{O campo da Alimentação e Nutrição}

O campo da "Alimentação e Nutrição" originase por caminhos outros, se comparada sua trajetória com a da SC. No interior da constituição da ciência moderna, os primeiros estudos sobre a composição química dos alimentos e seus nutrientes e implicações para o sucesso de empreendimentos comerciais encaminharam a "Nutrição" para a empiria e para o experimentalismo, resultando em crescente ascensão nos estudos nutricionais, desde as primeiras décadas do século passado 25 .

No Brasil, os marcos inaugurais de constituição do campo científico em questão também têm lugar na primeira metade do século passado, quando perspectivas de cunho biológico e naturalista encontram-se com ideais de crescimento econômico eprojetos políticos dos governos da época26.

A expressão "Nutrição" - como campo de profissionalização, de formação de pesquisadores, de geração de conhecimentos e de um vasto conjunto de práticas - vai-se estabelecendo, marcada por uma miríade de significados e praticamente nenhuma reflexão epistemológica sobre sua constituição eidentidade como campo esuas relações com outros campos da ciência e da vida queo tangenciam ecom el eestabelecem disputas variadas.

Se tomarmos o primeiro componente - o da profissionalização -, ao menos três principais núcleos de práticas se encontram de certa forma reconhecidos, num olhar mais afeito ao senso comum queà reflexão epistemológica: (1) a "Nutrição Clínica”, "Dietoterapia” ou "Terapia Nutricional", que, tomando por base a "dietética" como via privilegiada, opera a "prescrição dietoterápica" como tarefa central; (2) correntemente denominado "Administração deServiços deAlimentação, Produção de Refeições ou Alimentação de Coletividades", esse núcleo, partindo da "culinária de base nutricional" fundamentada na "dietética", segue conformando cardápios e providenciando sua execução, tendo na cozinha industrial seu lócus de ação; (3) por fim, o que vem sendo reconhecido como "Nutrição em Saúde Pública", "Nutrição Social (e Aplicada)" ou "Nutrição em Saúde Coletiva", para além de ter seu fundamento na dietética, como os dois primeiros, agrega, em distintas proporções, os núcleos constitutivos da SC, conforme procuraremos elucidar, constituindo o queconsideramos como o escopo daANSC.

Registre-seainda que, quando setrata deinstituições governamentais, no sentido de ações de poder edeestabelecimento de di retrizes, a terminologia passa a ser outra, incorporando a "Alimentação": Instituto Nacional de "Alimentação" eNutrição; Conselho Nacional deSegurança "Alimentar" e Nutricional; Direito Humano à "Alimentação"; Estratégias dePromoção de"Alimentação" Saudável, entre outras. Ainda assim, vem predominando, não só no plano do senso comum como também no espaço acadêmico, a visão equivocada de que o conceito "Nutrição" abarca não somente todas essas esferas de atuação profissional como também a multidimensionalidade do fenômeno alimentar-nutricional, repercutindo fortemente na pesquisa e na formação de graduação e pós-graduação.

Desse modo, no contexto brasileiro, não se pode falar em consenso no que concerne às terminologias para designação desse campo e seus núcleos, revelando-se, assim, profunda carência de esforços no sentido dessa reflexão, o que logo de início apontamos como uma das motivações para o exercício aqui empreendido. Sem isso, ao que parece, permaneceremos nessa espécie de Babel, misturando taxonomias eenglobando, sob o rótulo "Nutrição", dimensões epistemológicas distintas, limitando assim o conceito de "Alimentação" a mero nome-sinônimo.

Dentre outras consequências, reduzem-se a multidimensionalidade e a complexidade do ato alimentar aos elementos privilegiados pela vertente biológica. Assim reduzido, o campo da AN configurou-se, predominantemente, adequandose aos parâmetros de cientificidade da racionalidade científica moderna ${ }^{27}$. Dessa forma, vai-se afirmando como "boa ciência" aquela queseconstrói com enunciados derivados do método experimental e da tradição quantitativa de pesquisa, neutralizando-se dimensões fundamentais, como processos de subjetivação mediados pela comida, com consequências importantes para os estudos e intervenções em "Alimentação e Nutrição".

Não obstante, esse processo de hegemonia do modelo biomédico no campo vai encontrando resistências. Estudos voltados para o exame do estado nutricional dos brasileiros e das ações governamentais constituíram uma das bases para que o caráter social e humano do fenômeno se expressasse, assumindo tons politizados de denúncia contra a fome e as injustiças sociais a ela associadas. A essas iniciativas muitas outras viriam se somar, enfatizando o caráter históricosocial, a cultura e a dimensão col etiva da saúde, ainda que dentro de perspectivas como a higienista, preventivista ou de desenvolvimento da comunidade. Registre-seque, a essa época, a Saú- 
de Coletiva inexistia como campo, movimento ou paradigma.

Ao longo do percurso de constituição do campo da "Alimentação e Nutrição", uma ocorrência viria marcá-lo de forma indelével: 0 encontro com a SC. A partir de então, a concepção vigente da "Nutrição" passa a ser problematizada, evidenciando sua multidimensionalidade, movimento queviria a repercutir fortementesobre o campo AN, abrindo-se novas reflexões em busca de outros paradigmas capazes de subsidiar projetos inovadores de alimentação voltados para a saúde humana, em sentido amplo.

As intensas transformações resultantes do encontro entre esses dois campos resultam num complexo que aqui identificamos como "Alimentação e Nutrição em Saúde Coletiva". Trata-se de um conjunto intrincado demovimentos nos planos epistemológico e político, com repercussões de grande impacto nos campos de origem AN e SC, reconfigurando-0S, pari passu, com sua própria constituição. Seu ordenamento interno será o objeto de que nos ocuparemos quando tratarmos do tópico "Alimentação e Nutrição em Saúde Coletiva".

Esse encontro vivo de campos diferenciados é marcado por forças, ritmos, temperaturas, sons e sabores distintos, elementos metafóricos de que lançamos mão na tentativa de evidenciar a dinâmica complexa quando seus núcleos se relacionam, derivando o que postulamos como ANSC. Desse modo apontaremos, na sequência, os construtos resultantes desse encontro, destacando ainda algumas características e tensões manifestas em cada um deles, persistindo, ao que parece, a polarização entre a biomedicina e as abordagens humanísticas a que já fizemos alusão quando tratamos dos campos seminais.

N esse exercício, vislumbra-se a perspectiva, ora mais intensa, ora mais sutil, de que é necessário investir na aproximação, no confronto, nas contradições entre esses campos e núcleos de saberes e práticas, em busca da superação dialética dessa polarização, tal como exigem os desafios cada vez mais intensos que se apresentam para a saúde, alimentação etantas outras esferas da vida humana.

\section{Alimentação e Nutrição em Saúde Coletiva}

0 arcabouço teórico-metodológico da Epidemiologia constituiu-se como um dos primeiros fundamentos de vinculação entre a "Alimentação e Nutrição" e a "Saúde Coletiva", ao traba-
Ihar com diagnósticos de estado nutricional em populações pobres, trazen do à tona os sofrimentos e a degradação humana impostos pela fome e pelas doenças carenciais, associadas a doenças transmissíveis em um contexto de forte iniquidade social, contradizendo o "milagre brasileiro". Os programas inaugurais do que, mais tarde, viria a conformar a rede de pós-graduação em Saúde Coletiva (denominados, à época, e alguns até hoje, com distintos rótulos) apresentavam-se como loci privilegiados para atender às demandas por formação crítica, propiciando o desenvolvimento de habilidades no uso de metodologias que vinculavam fome/desnutrição e mortalidade infantil a renda, classe, dentre outras "variáveis sociais". M ediante o emprego dos aportes da Epidemiologia Social, tornou-se possível articular informações sobre agravos que acometiam indivíduos ao seu contexto histórico-social, com vistas a esclarecer cenários e determinantes ea subsidiar políticas de saúde. Paulatinamente, fenômenos conceituados como transições demográfica, epidemiológica enutricional redirecionariam significativamente o foco das pesquisas para a obesidade e as doenças crônicas e degenerativas, exigindo novos investimentos metodológicos, aspecto que, agregado às preocupações anteriores, se desdobra no que hoje se concebe como "Epidemiologia Nutricional".

Em compasso com o movimento que vem se dando no âmbito da SC, observa-se a crescente complexidade nas metodologias que operam na linguagem das variáveis, marca da Epidemiologia N utricional, fundamentada nas Ciências $\mathrm{Na-}$ turais, acarretando uma naturalização de fenômenos multidimensionais como saúde ealimentação, ao tempo que se constata um afastamento, cada vez mais acentuado, das abordagens sociais também no que tange a práticas alimentares. A operacionalização do método toma lugar de destaque em relação às reflexões teóricas acerca das relações humanas mediadas pela comida, fixando-se no seu desfecho: o estado nutricional. Mais uma vez retrata-se a força do método em detrimento do enunciado, uma das marcas da racionalidade científica moderna ${ }^{20}$.

Esse perfil se identifica fortementecom a economia dominante no campo científico. Ao fixarsenum âmbito mais técnico enaturalizado, erenunciando à reflexão teórica eepistemológica, 0 referencial epidemiológico é a base sobre a qual se consolida a Epidemiologia Nutricional, concorrendo talvez mais para a fragmentação de saberes e práticas na "Saúde" ena "Alimentação e Nutrição" do que para sua construção em fun- 
damentos interdisciplinares, quando poderia ocorrer o inverso. Para tanto, caberia um investimento mais intenso em uma"Epistemologia da Epidemiologia" que pudesse ampliar seu al cance e, ao lado disso, apontar seus limites.

Esse processo, evidentemente, não se dá sem resistências internas. A Epidemiologia Nutricional de cunho biomédico vai sendo renomeada, ainda que em proporções minoritárias, aludindo a visões mais ampliadas de seus objetos de estudo: "Determinação social do estado nutricional" ou "Determinantes individuais e contextuais do estado nutricional", dentre outras nomenclaturas, aparecem como expressões de vínculos com a Epidemiologia Social, mais identificada com a reflexão conceitual acerca de suas práticas, buscando contextualizá-las histórica e socialmente.

Repetem-se, portanto, como seria de se esperar, movimentos já antes constatados, quando visitamos esse núcleo no campo da SC, no qual a Epidemiologia é marcada por tensões externas e internas, ao tempo que também vai ao encontro do campo das Políticas, possibilitando novas frentes.

Tal como na SC, a aproximação da AN às Ciências Humanas e Sociais implicou reorientação significativa dos rumos do que até então vinha sendo reconhecido apenas como "Nutrição". Esse enfoque inseriu efetivamente a "Alimentação" no campo, com repercussões ainda que tímidas em alguns casos, mas definitivas, amplas e profundas em outros.

0 referencial das $\mathrm{CHS}$, conforme vimos, fortemente presente e mesmo seminal na conformação do campo da "Saúde Coletiva", trouxe ao campo AN questionamentos acerca dos fundamentos da "Nutrição" e de seu alcance para descrever, explicar e responder a questões como determinação social da fome e de outros fenômenos que escapam aos modelos causais e lineares, configurando, gradualmente, novos objetos e ampliando fronteiras.

Ilustrando esse movimento, aos poucos vãose afirmando construções fundadas na incorporação da dimensão psicoafetiva e de mediações simbólicas, ou seja, da produção subjetiva, com o reconhecimento da natureza multidimensional eholística da relação homem-comida ${ }^{27}$, cujos significados remetem ao que hoje entendemos por "integralidade" do humano, no âmbito do cuidado em saúde, um dos princípios do ideário do movimento sanitário e referência no âmbito do sistema de saúde pretendido pelo campo da SC ${ }^{28}$.

Em seu interior, al gumas vertentes mais específicas vão-se constituindo, abrangendo relações
entreAlimentação e Sociedade, mediadas pela cultura e pelos processos de subjetivação. Todo esse conjunto possibilitado pelo encontro das $\mathrm{CHS}$ com os objetos do campo AN é aqui entendido como o escopo das "Ciências Humanas e Sociais em Alimentação e Nutrição", segundo conjunto de saberes centrais na constituição da ANSC.

Com base nesse enfoque, vão-se estabelecendo, aos poucos, demarcações eobjetos tais como: - lugar protagonizado pelo atores sociais em suas relações coletivas; a compreensão de ritos e inclusão das subjetividades como fenômenos situados, inexoravelmente, no seu contexto histórico; o potencial da análise crítica no estudo de intervenções e na formação de profissionais; a revisão da práxis no mundo da ciência. Um novo lugar, portanto, para "pensar a 'Alimentação e Nutrição'" como uma possibilidade de realização humana.

Estudos clássicos abordando relações sociais mediadas pela comida no Brasil ${ }^{29-32}$, bem como os que resgatam a trajetória e permitem refletir sobre alimentação, nutrição, saúde, sociedade e cultura, são ainda pontuais se comparados com outros saberes que circulam na AN SC. M as tais fenômenos constituíram objetos de estudos aprofundado ${ }^{33,34}$ desde os primórdios da constituição da ANSC, ocupando até hoje lugar de destaque no cerne dos debates sobre seus rumos.

A produção científica no campo alimentar vem sendo discutida desde a década de $1980^{35-38}$; mais recentemente, a interfaceAN ecultura, bem como os investimentos na discussão sobre pesquisas e atores em movimento nesseâmbito, vem-seconstituindo em objeto de reflexão ${ }^{39}$. Os autores convergem quanto ao crescimento da produção acadêmica sobre alimentação e cultura no interior dos campos envolvidos, destacando-se, entretanto, significativas limitações quanto aos fundamentosteórico-metodológicosquesubsidiam boa parte dessa produção, quando se desenvolve no campo da Saúde, constatando-se ocorrência de superficialidades e inconsistências em significativa parcela das análises empreendidas, o que também é fato para outros campos da saúde e também para uma parcela do que se produz na SC.

Em que pesem essas insuficiências conceituais, cuja superação deve ser sistematicamente perseguida - contexto no qual, a despeito da ressalva assinalada, a "Saúde Coletiva" resiste como uma ponte importante, possibilitando novos objetos e sínteses - , tais incursões vêm abrindo novos horizontes e trazendo possibilidades de repensar os paradigmas dominantes, suas possibilidades e limites. Sua contribuição maior tal- 
vez seja essa insistência na necessidade de ousar pensar a alimentação e a nutrição como fenômenos sociais - contribuição construída no seio dessa imbricação: Alimentação e Nutrição em Saúde Coletiva.

Partindo também de abordagens de cunho humanista, proposições formuladas no âmbito do Estado brasileiro relativas à AN foram objeto de questionamentos que se intensificaram e ganharam força sob influência da SC. Análises de cunho sociológico ${ }^{26,40,41}$ confrontavam discursos epráticas identificadas nas ações governamentais formuladas em face dos estudos que evidenciavam a fome e a desnutrição, denunciando seu caráter intrinsecamente reprodutor do capital e da degradação da vida humana. Constitui-se, assim, um terceiro conjunto, grosso modo identificado como "Políticas de Alimentação e Nutrição".

Conforme já mencionado quando examinamosna SC a Epidemiologia, em sua vertente crítica, as profundas desigualdades sociais persistindo com um milagroso crescimento econômico traziam à tona contradições desse modelo, sendo a fome uma de suas expressões mais perversas. Acompanhando o movimento de constituição de um pensamento crítico em saúde (e, também, em “Nutrição") na América Latina e no Brasil, al guns autores alinhados à vertente sóciohistórica, inspirada no legado das Ciências Humanas e Sociais $\mathrm{s}^{26,42}$, empreendiam a tarefa de, contra-hegemonicamente, auferir maior visibilidade à dimensão social ou socioeconômica ine rente ao binômio alimentação e nutrição e seus desdobramentos.

Caberecuperar que, nesse cenário, institui-se uma Política Nacional de Alimentação e Nutrição, sendo o I Programa Nacional de Alimentação e Nutrição (Pronan) um marco, atraindo não somente análises de cunho epidemiológico no campo da $A N$, mas também aquelas voltadas às políticas então implementadas, no sentido de apontar seus limites e contradições. Além disso, como movimento político, a Saúde Coletivajá se encontra, à época, em plena conformação, buscando implementar um projeto para o setor saúde - a Reforma Sanitária - , enquanto no campo da AN também se desenhavam novas propostas para o país, buscando na intersetorialidade e na interdisciplinaridade os fundamentos para sua constituição, evidenciando a conjugação de esforços desses campos.

Conformam-se, assim, as bases para o que hoje se materializa através de um complexo conjunto de políticas, estratégias, programas de governo assumidamente de "Alimentação e Nutri- ção", que transbordam já a Saúde e o Estado, embrenhando-se nos lugares da definição de leis e justiça e alcançando a esfera da sociedade civil, relação na qual sevem investindo fortemente, sendo a fome assumida como prioridade na agenda política do Estado. E ainda queo debate epistemológico sobreconceitose objetos do campo alimentar-nutricional não tenha aqui seu nascedouro e lócusprincipal deevolução, a concretude dasações no âmbito desse núcleo de saberes e práticas colabora fortemente para evidenciar a "alimentação" e suas distinções em relação à "nutrição".

Da mesma forma como apontamos em outros momentos desta reflexão, tal movimento não se dá sem tensões: se, por um lado, a "Alimentação" ganha lugar e coloca o quão além dos referenciais biomédicos seu exame se encontra, de outro a inserção da "Nutrição" mantém o espaço das perspectivas biomédicas e normalizadoras, sem que disso se apercebam, em muitos casos, seus formuladores e/ou executores e mesmo aqueles que se propõem a desenvolver análises críticas.

No interior dessa dinâmica que, simultaneamente, explicita e aprofunda as tensões conceituais que busca enfrentar, deve-se considerar que, tal como apontamos quando tratamos do núcleo de saberes "Políticas, planejamento e gestão em saúde" da Saúde Coletiva, a exigência de foco nas ações concretas e imediatas no âmbito das "Políticas de Alimentação e Nutrição" pode afastar os atores da necessária reflexão conceitual acerca dos paradigmas em disputa. Distintamente, porém, do que afirmamos para a SC, não se pode dizer de al gum período de dominância desse núcleo sobreo conjunto da Alimentação e N utrição, tampouco sobre a Alimentação e Nutrição em Saúde Coletiva. Não se pode negar, todavia, a crescente expressão nacional e internacional, sobretudo no âmbito da segurança alimentar, construída nos anos recentes (Governo Lula), em que a fome e a questão alimentar figuram como ideiasforça dos planos de governo, ampliando sobremaneira a indução e as possibilidades de financiamento para estudos nesse âmbito. Ressalte-se quetais incentivos ultrapassam largamenteaqueles, restritíssimos, destinados a estudos sobre alimentação, sociedade, cultura e subjetividades.

No que tange à construção interna da interdisciplinaridade no campo ANSC, a aproximação entre "Epidemiologia nutricional" e "Políticas de alimentação e nutrição" vem-se intensificando e ganhando, inclusive, solidez institucional; contudo, ainda são limitados os vínculos desse par com as potencialidades do referencial 
das CHS. Com efeito, persistem aquelas de cunho mais macroeconômico voltadas para a crítica a estruturas de Estado e à organização da sociedade sob o domínio do capital, que tiveram grande força no início da constituição do campo ANSC. Análises que incluam abordagens que permitam mediações mais refinadas não apenas do contexto macro, mas da microfísica na qual se tece a práxis no setor, ainda são um devir.

\section{Considerações finais}

Empreendemos aqui um primeiro esforço buscando, conforme logo de início assinalamos, re duzir a "nebulosidade" que caracteriza o que de marcamos como Alimentação e Nutrição em Saúde Coletiva, no intuito de iluminar, com alguns elementos, esse que tem sido um objeto permanente em nossas reflexões.

No percurso desenvolvido, procuramos evidenciar a existência de um movimento marcado pelo encontro profícuo entre o campo da "Saúde Coletiva" e uma parcela do campo da "Alimentação e Nutrição", ou, mais precisamente, um de seus núcleos, protagonizado por atores orientados por saberes diferenciados dos demais núcleos nesse campo. Conforme procuramos sustentar, tais protagonismos, que postulamos como derivados do contato com os núcleos de saberes queidentificam aSC, deram origem aum núcleo específico de saberes e a práxis distintas, no âmbito da "Alimentação e Nutrição", correspondendo ao que denominamos "Alimentação e Nutrição em Saúde Coletiva".
Não obstante, reconhecermos que, nesse núcleo, os elementos presentes em seu nascedouro - iniciativas, discussões e intervenções de caráter populacional - foram profundamente reconfigurados mediante a reconstrução de conceitos operada pelos saberes da SC, em especial aquela possibilitada pelo referencial crítico adotado no pensamento social em saúde, operando um movimento permanente desuperação dial ética. Trata-se, como vimos, de um processo marcado, desde 0 início, por tensões entre os paradigmas biológico e social, que ainda se configura como importante desafio a ser enfrentado, caminho que poderá abrir portas para a aproximação com outros campos da ciência, tanto os de cunho mais prático como os dirigidos à reflexão conceitual.

Ao nos referirmos à Alimentação em Nutrição em Saúde Coletiva, referimo-nos, portanto, ao que se poderia metaforicamente caracterizar como uma "mútua fertilização": de uma parte, operada pel os núcleos de saberes da "Saúde Coletiva" ao visitarem o campo "Alimentação e Nutrição", fenômeno que, sustentamos, se espraia por vários outros campos da saúde, merecendo análises ulteriores. Dial eticamente, os objetos oriundos do campo "Alimentação e Nutrição" brilham na produção então nascentequeemergedessa fertilização, no interior da "Saúde Coletiva".

Desvela-se, assim, um duplo movimento mediante o qual o campo "Alimentação e Nutrição" se deixa inocular por todos os núcleos de saberes da Saúde Coletiva, ao tempo que nesta deixa suas marcas. 


\section{Referências}

1. Bourdieu P. O campo científico. In: Ortiz R, organizador. Pierre Bourdieu. São Paulo: Ática; 1983.

2. Khun T. A estrutura das revoluções científicas. São Paulo: Perspectiva; 2003.

3. Gramsci A. Cadernos do cárcere. Rio de Janeiro: Civilização Brasileira; 2000.

4. Nunes ED. Saúde Coletiva: história recente, passado antigo. In: Campos GWS, M inayo MCS, Akerman M, Drumond Junior M, Carvalho YM. Tratado de saúde coletiva. $2^{\underline{a}}$ ed. São Paulo: Hucitec; Rio de Janeiro: Editora Fiocruz; 2009.

5. Campos GWS. Saúde Pública e Saúde Coletiva: campo e núcleo de saberes e práticas. Cien Saude Colet 2000; 5(2):219-230.

6. Campos GWS, Minayo MCS, Akerman M, Drumond Junior M, Carvalho YM. Tratado de Saúde Coletiva. São Paulo: Hucitec; Rio de Janeiro: Editora Fiocruz; 2009.

7. Paim JS, Almeida Filho N. Saúde Coletiva: uma nova saúde pública; ou campo aberto a novos paradigmas? Rev Saude Publ 1998; 32(4):299-316.

8. Nunes ED. Pós-graduação em Saúde Coletiva no Brasil: histórico e perspectivas. Physis 2005; 15(1):1338.

9. Camargo Jr KR. Os caminhos da Saúde Coletiva. Physis 2008; 18(2):185-187.

10. Bosi MLM, Paim JS. Graduação em Saúde Coletiva: subsídios para um debate necessário. Cad Saude Publica 2009; 25(2):236-237.

11. Foucault M. Microfísica do poder. Rio de Janeiro: Graal; 1979.

12. Rosen G. U ma história da Saúde Pública. São Paulo: Unesp; 1994.

13. Nunes ED. As ciências sociais em saúde na América Latina: tendências e perspectivas. Brasília: O pas; 1985.

14. Nunes ED. Ciencias sociales y salud: el pensamiento recente de algunos investigadores. Cuadernos M edico-Sociales 1994; 69:67-93.

15. Donnangelo MC, Pereira L. Saúde e sociedade. São Paulo: Duas Cidades; 1976.

16. Paim JS. Desafios para a Saúde Coletiva no século XXI. Salvador: EdUFBA; 2006

17. Loyola MAR. A saga das Ciências Sociais na área da Saúde Coletiva: elementos para reflexão Physis 2008; 18(2):251-275.

18. Czeresnia D. Epidemiologia, Ciências Sociais, integração das ciências. Rev Saude Publica 2008; 42(6):1112-1117.

19. Barata RCB. Epidemiologia e saber científico. Revista Brasileira de Epidemiologia 1998; 1:14-27.

20. Luz MT. Natural, racional, social: razão médica e racionalidade moderna. São Paulo: Hucitec; 2004.

21. M ercado FJ, Bosi M LM. Notas para um debate In: Bosi M LM, M ercado FJM. Pesquisa qualitativa de serviços de saúde. Petrópolis: Vozes; 2006.

22. Ayres JR. U ma concepção hermenêutica de saúde. Physis 2007; 17(1):43-62.

23. Paim JS, Teixeira CF. Política, planejamento e gestão em saúde: balanço do estado da arte. Rev Saude Publica 2006; 40(n. esp.):73-78.
24. Vasconcelos FAG. O nutricionista no Brasil: uma análise histórica. Rev Nutr 2002; 15(2):127-138.

25. Vasconcelos FAG. Fome, eugenia e constituição do campo da nutrição em Saúde Pública de Pernambuco: uma análise de Gilberto Freyre, Josué de Castro e N elson Chaves. Hist Cienc Saude-M anguinhos 2001; 8(2):315-339.

26. Bosi M LM . A face oculta da nutrição: ciência e ideologia. Rio de Janeiro: Espaço e Tempo, UFRJ; 1988.

27. Bosi MLM. A nutrição na concepção científica moderna: em busca de um novo paradigma. Rev Nutr 1994; 7(1):32-47.

28. Pinheiro $R, M$ attos RA, organizadores. Os sentidos da integralidade na atenção e no cuidado à saúde. Rio de Janeiro: Cepesc; 2001.

29. Freyre G. Açúcar: uma sociologia do doce. São Paulo: Companhia das Letras; 1997.

30. Cascudo LC. História da alimentação no Brasil. Belo H orizonte: Itatiaia; São Paulo: Editora da Universidade de São Paulo; 1983.

31. Strauss CL. 0 cru e o cozido. M itológicas 1. São PauIo: Cosac \& Naify; 2004.

32. DaM atta R. 0 que faz do Brasil, Brasil? Rio de Janeiro: Rocco; 2001.

33. Ypiranga L, Gil MF. Formação profissional do nutricionista: por que mudar? In: Cunha DTO, Ypiranga $L$, Gil M F, organizadores. II Seminário Nacional sobre o Ensino de Nutrição. Goiânia: Febran, 1989. p. 20-36.

34. Bosi MLM. Profissionalização e conhecimento: a Nutrição em questão. São Paulo: Hucitec; 1996.

35. Canesqui AM. Antropologia e Alimentação. Rev Saude Publ 1988; 22(3):207-216.

36. Canesqui AM. Comentários sobre os estudos antropológicos da alimentação. In: Canesqui AM, Garcia RWD. Antropologia e Nutrição: um diálogo possível. Rio de Janeiro: Editora Fiocruz; 2005. p. 23-47.

37. Canesqui AM. Pesquisas qualitativas em nutrição e alimentação. Rev Nutr 2009; 22(1):125-139.

38. Canesqui AM, Garcia RWD, organizadoras. Antropologia e Nutrição: um diálogo possível. Rio de Janeiro: Editora Fiocruz; 2005.

39. Silva JK, Prado SD, Carvalho MCS, Ornelas TFS, Oliveira PF. Alimentação e cultura como campo científico no Brasil. Physis 2010; 20(2):413-441.

40. L'Abbate $\mathrm{S}$. As políticas de alimentação e nutrição no Brasil: I. Período de 1940 a 1964. Rev Nutr 1988; 1:87-138.

41. L'Abbate S. As políticas de alimentação e nutrição no Brasil: II. A partir dos anos setenta. Rev Nutr 1989; 2:7-54.

42. Vasconcelos FAG. A política social de alimentação e nutrição no Brasil: acumulação de capital e reprodução da fome/desnutrição. Saúde em Debate 1988; 23:42-49. 